\title{
EVALUATION OF DOCTORS' ASSESSMENT OF HEALTHY LIFESTYLE: CROSS-SECTIONAL STUDY
}

\author{
Kostyantyn Balashov \\ Department for Communications ${ }^{l}$ \\ kostyantyn.balashov@gmail.com \\ Olesya Hulchiy ${ }^{1}$ \\ olesya.hulchiy@nmapo.edu.ua \\ Gennady Slabkiy \\ Department of Public Health \\ Uzhhorod National University \\ 3 Narodna sq., Uzhhorod, Ukraine, 88000 \\ g.slabkiy@uzhnu.edu.ua \\ ${ }^{1}$ Shupyk National Healthcare University of Ukraine \\ 9 Dorohozhytska str., Kyiv, Ukraine, 04112
}

\begin{abstract}
The aim. To study the factors of doctors' assessment of their lifestyle as a healthy one, as well as their readiness to take practical measures for health maintenance.

Materials and methods. 167 doctors representing all macro regions of Ukraine were interviewed: the levels of awareness of myths about NCDs, locus of control and readiness to take practical measures aimed at health maintenance were determined. The main acting forces were determined by factor analysis. Cluster analysis was performed on the basis of the obtained factors using hierarchical (Ward's method) and non-hierarchical (k-means method) clustering methods.

Results. The following concepts were assessed: Myths about NCDs (11 factors, 3 elements, 4 clusters), locus of control (12 factors, 3 elements, 4 clusters), factors influencing health behavior (12 factors, 3 elements, 4 clusters), readiness to take practical measures aimed at health maintenance ( 22 factors, 4 elements, 2 clusters). Factors that positively and negatively affect a person's assessment of the lifestyle as a healthy one were identified.

Conclusions. The selected subgroups (clusters) of respondents are a simple and effective method of building a better understanding of the target audience of campaigns to promote healthy lifestyles, which after proper clarification, verification and development of a reliable measurement tool can be used to create targeted messages for each population group after a proper clarification and verification.

Keywords: Public health, non-communicable diseases, health communication healthy lifestyle, cluster analysis.
\end{abstract}

DOI: $10.21303 / 2504-5679.2021 .001709$

\section{Introduction}

Living a healthy lifestyle is an internationally recognized approach of preventing the onset and progression of non-communicable diseases (NCDs) [1]. Healthy living traditionally includes balanced diet, physical activity, quitting bad habits (smoking, abusive drinking behavior), etc. WHO pays great attention to the prevention of NCDs, but the communication aspect in programs to combat non-communicable diseases is fundamentally less developed than in infectious diseases or focuses on advocacy mechanisms [2]. The major NCDs responsible for $71 \%$ of deaths that occurred globally included cardiovascular diseases, cancers, chronic respiratory diseases, and diabetes [3].

At the same time, according to T. Abraham, simplifying communication and promoting ready-made solutions instead of open inclusive dialogue is a mistake. Such actions are more aimed to convince society of the need to take certain actions than at making informed choices [4].

According to research, doctors remain key sources of information about health in Ukraine and throughout the world [5]. It is likely that doctors' personal beliefs about healthy lifestyle might influence the effectiveness of informing patients about NCD preventive measures. Since the late 2000 s role of the Internet as a channel of health information has grown [6], but the part of evidencebased sources of information is still low [7]. Evidence of the positive effect of discussing online health information with the physician was found [8]. 
Social marketing has offered an effective framework for developing health promotion programs and created a new paradigm in which consumers are involved in solving the problem. The marketing approach focuses on encouraging the voluntary exchange of resources rather than an aggressive promotion that makes free choice impossible [9].

S. Greer and K. Bryant compared the approach proposed by social marketing with the educational approach and legal constraints [10]. Referring to M. Rothschild [11], the authors argue that education informs and persuades people to accept healthy behavior voluntarily, realizing its benefits. Marketing influences behavior by offering alternative choices, and changes the environment in a way that makes healthy behavior more profitable, and communicates this more cost-benefit ratio to the target audience.

Formative research is designed to examine the factors needed to segment the audience and the factors that will help to change behavior [9]. The purpose of segmentation is to identify homogeneous subgroups (to create relevant messages) and segments that will be targeted for distribution and communication channels [12]. One of the more correct ways to create such segments is the application of cluster analysis, based on psychographic factors [13]. The main concepts which were included in the study described in the article [14].

Therefore, the paper is aimed at studying the factors of doctors' assessment of their lifestyle as a healthy one, identification of the readiness to take practical measures for health maintenance, and discovering the homogenous groups (clusters) of physicians.

\section{Materials and Methods}

To determine the beliefs and awareness of doctors on NCDs, their beliefs about healthy lifestyle and actions taken to prevent NCDs, there was a conducted research, the details of which are described in [15]. At the first stage, 167 doctors representing all macroregions of Ukraine were interviewed: the levels of awareness of myths about NCDs, locus of control and readiness to take practical measures aimed at health maintenance were determined.

The respondents were informed about the study being voluntary and anonymous. The questionnaire was filled in electronically. No personal data was collected.

According to modern approaches the psychographic characteristics were chosen as a basis for analysis [16]. Some factors of cultural background: occupation and educational level, social environment were assessed [17]. The reliability of the investigated concepts was assessed (Cronbach's alpha) and for each concept, the main acting forces were determined (factor analysis) [18].

Factor scores that were mainly in the range from -3 to +3 were calculated for each respondent. Cluster analysis was performed on the basis of the obtained factors. The result was considered acceptable with more than $70 \%$ coincidence of models formed using hierarchical (Ward's method) and non-hierarchical ( $k$-means method) clustering methods [19].

The determinants of doctors' assessment of their lifestyle as a healthy one were defined using linear regression analysis. For identification of statistically significant differences methods of pairwise comparison with application of Bonferroni adjustment for rates and analysis of variance (ANOVA) for averages were used.

To understand the structure of doctors' awareness and beliefs, the following concepts were assessed:

1. Myths about NCDs (11 factors, 3 elements, 4 clusters).

2. Locus of control (12 factors, 3 elements, 4 clusters).

3. Factors influencing health behavior (12 factors, 3 elements, 4 clusters).

4. Readiness to take practical measures aimed at health maintenance ( 22 factors, 4 elements, 2 clusters).

The factors of each concept were subjected to factor analysis in order to determine the main acting forces and reduce the number of variables.

\section{Research results}

The division into groups (cluster formation) was performed to characterize the doctors according to the obtained factors. In each case of clustering, preference was given to the method of cluster analysis, which provided a more equal distribution of respondents between clusters. 
The concept of myths about NCDs (Cronbach's alpha 0.76 ) consists of 11 factors that describe respondents' attitudes to common misconceptions about NCDs, such as the impact of lifestyle on NCD development; quality and duration of life with NCDs; the relation between habits, genetic factors and medical care in NCD development; insufficient expenses on preventive measures; prevalence and mortality from NCDs in Ukraine and in the world; the relationship between the prevalence of NCDs and the economic level of the country.

The concept was divided into 3 elements (Kaiser-Meyer-Olkin measure of sampling adequacy (KMO) 0.78): attitude to the prevalence of NCDs, personal dimension of NCDs, economic dimension of NCDs. Coincidence of clusters formed by hierarchical and non-hierarchical methods was more than $75.4 \%$ (Table 1).

For better understanding of the cluster models, there were used moderators: the proportion of doctors who smoke, the proportion of doctors with NCD or whose relatives have NCD, and the average score supporting the suggestion that habits have a greater influence on NCD development than medicine. In the questionnaire, there was the following question: «Do you agree that our habits have a greater influence on NCD development than the possibilities of medicine?» $(1-« \mathrm{Com}-$ pletely disagree». 10 - «Completely agree»).

Table 1 shows that the representatives of the first cluster are sufficiently informed about all three elements with the predominance of personal dimension of NCDs, which is confirmed by lower percentage of smokers and the highest support of the suggestion about the importance of habits in NCD development.

The doctors of the second cluster have positive indicators of the prevalence and economic dimension of NCDs, but a negative indicator of personal dimension, which is probably related to the highest share of smokers among clusters (25\%).

The concept of the locus of control (Cronbach's alpha 0.92) describes respondents' beliefs about the structures responsible for human health. Twelve individual questions were provided (the level of responsibility was determined according to a 10-point Likert scale), which assessed the level of responsibility for human health of the WHO, state and local authorities, the Ministry of Health and health departments in the regions, representatives of medical science and education, the press, the employer, doctors, non-governmental organizations and volunteers, relatives and friends, as well as the individual.

The concept was divided into three elements (KMO 0.92): directive locus of control (government responsibility), collective (community responsibility) and proactive (individual responsibility). Coincidence of clusters formed by hierarchical and non-hierarchical methods was more than $83.2 \%$ (Table 2 ).

The representatives of the first cluster are characterized by the highest indicators of directive and collective responsibility, and the second and third clusters - by proactive responsibility. The doctors of the third cluster have the highest level of NCDs and the lowest value of the collective responsibility.

Table 1

Groups of doctors by NCDs myth elements

\begin{tabular}{lccccccc}
\hline & \multicolumn{3}{c}{ Factor scores, Mean \pm SD } & \multicolumn{3}{c}{ Moderators } \\
\cline { 2 - 8 } Cluster & $\begin{array}{c}\text { attitude to NCD } \\
\text { prevalence }\end{array}$ & $\begin{array}{c}\text { personal } \\
\text { dimension of } \\
\text { NCDs }\end{array}$ & $\begin{array}{c}\text { economic } \\
\text { dimension of } \\
\text { NCDs }\end{array}$ & $\begin{array}{c}\text { smokers, } \\
\%\end{array}$ & $\begin{array}{c}\text { NCD in } \\
\text { doctors, \% }\end{array}$ & $\begin{array}{c}\text { NCD in } \\
\text { relatives, } \\
\%\end{array}$ & Habits vs medicine \\
\hline 1 (66 pers.) & $0.17 \pm 0.48$ & $\mathbf{0 . 7 6} \pm \mathbf{0 . 4 9}$ & $\mathbf{0 . 4 9} \pm \mathbf{0 . 6 1}$ & 12.1 & 53.0 & 77.3 & $9.1 *$ \\
2 (44 pers.) & $\mathbf{0 . 4 0} \pm \mathbf{0 . 4 2}$ & $-0.98 \pm 0.79$ & $\mathbf{0 . 4 0} \pm \mathbf{0 . 5 6}$ & $25.0^{*}$ & 59.1 & 84.1 & 7.0 \\
3 (21 pers.) & $-1.98 \pm 1.31$ & $-0.30 \pm 0.68$ & $-0.05 \pm 1.21$ & 14.3 & 61.9 & 90.0 & 7.1 \\
4 (36 pers.) & $\mathbf{0 . 3 4} \pm \mathbf{0 . 6 2}$ & $-0.02 \pm 0.96$ & $-1.36 \pm 0.51$ & 11.1 & 58.3 & 88.9 & 7.4
\end{tabular}

Note: * - the moderator has statistically significant difference at the level of $p<0.05$ from other clusters. Factor scores are mainly in the range from -3 to +3 
Table 2

Groups of doctors by locus of control elements

\begin{tabular}{lccccccc}
\hline \multirow{2}{*}{ Cluster } & \multicolumn{3}{c}{ Factor scores, Mean \pm SD } & \multicolumn{3}{c}{ Moderators } \\
\cline { 2 - 7 } & directive LC & collective LC & proactive LC & Smokers, \% & $\begin{array}{c}\text { NCD in } \\
\text { doctors, \% }\end{array}$ & $\begin{array}{c}\text { NCD in } \\
\text { relatives, \% }\end{array}$ & Habits vs medicine \\
\hline 1 (63 pers.) & $0.72 \pm 0.54$ & $0.60 \pm 0.64$ & $0.08 \pm 0.33$ & 20.6 & 52.4 & 87.3 & 7.9 \\
2 (50 pers.) & $-0.97 \pm 0.54$ & $0.40 \pm 0.7$ & $0.23 \pm 0.44$ & 10.0 & 48.0 & 82.0 & 8.0 \\
3 (45 pers.) & $0.09 \pm 1.1$ & $-1.23 \pm 0.5$ & $0.32 \pm 0.21$ & 17.8 & $73.3 *$ & 82.2 & 8.1 \\
4 (9 pers.) & $-0.15 \pm 0.71$ & $-0.27 \pm 0.9$ & $-3.47 \pm 1.99$ & 0.0 & 55.6 & 62.5 & 7.1
\end{tabular}

Note: * the moderator has statistically significant difference at the level of $p<0.05$ from other clusters. Factor scores are mainly in the range from -3 to +3

The concept of the factors influencing health behavior (Cronbach's alpha 0.85) determined respondents' assessment of the favorable or adverse effects of certain factors on their health, including daily routine, diet, financial situation, social environment, family traditions, work place, habits, profession, busyness, mood, environmental factors, the presence of close family members, the accessibility of health information.

The concept was divided into three elements (KMO 0.84): lifestyle (internal environment), constant environment (external environment) and sociability (information acquisition). Coincidence of clusters formed by hierarchical and non-hierarchical methods was more than $77.2 \%$ (Table 3).

Table 3

Groups of doctors by elements of influence on health behavior

\begin{tabular}{cccccccc}
\hline \multirow{2}{*}{ Cluster } & \multicolumn{3}{c}{ Factor scores, Mean \pm SD } & \multicolumn{3}{c}{ Moderators } \\
\cline { 2 - 7 } & lifestyle & $\begin{array}{c}\text { constant } \\
\text { environment }\end{array}$ & sociability & Smokers, \% & $\begin{array}{c}\text { NCD in } \\
\text { doctors, \% }\end{array}$ & $\begin{array}{c}\text { NCD in } \\
\text { relatives, \% }\end{array}$ & Habits vs medicine \\
\hline 1 (57 pers.) & $0.38 \pm 0.41$ & $0.61 \pm 0.61$ & $0.72 \pm 0.43$ & 10.5 & $42.1^{*}$ & $73.2^{*}$ & 8.1 \\
2 (30 pers.) & $0.27 \pm 1.04$ & $-1.62 \pm 0.68$ & $-0.29 \pm 0.1 .06$ & 23.3 & 73.3 & 86.7 & 8.2 \\
3 (61 pers.) & $0.10 \pm 0.6$ & $0.32 \pm 0.52$ & $-0.77 \pm 0.76$ & 14.8 & 62.3 & 90.2 & 7.7 \\
4 (19 pers.) & $-1.87 \pm 0.1 .2$ & $-0.29 \pm 0.63$ & $0.77 \pm 0.69$ & 21.1 & 57.9 & 84.2 & 7.7
\end{tabular}

Note: * the moderator has statistically significant difference at the level of $p<0.05$ from other clusters. Factor scores are mainly in the range from -3 to +3

The representatives of the first cluster consider all three elements to have favorable effect on health; they also have lower incidence of NCDs, as well as their relatives, compared to other clusters. The representatives of the fourth cluster consider the influence of the sociability element to be favorable, and the lifestyle element to be unfavorable.

The list of questions that formed the concept of «Readiness to take practical measures aimed at health maintenance» was clarified using correlation analysis: for further analysis, a group of questions was identified that correlate strongly and moderately $(r \geq 0.3)$. According to the results of Cronbach's alpha determination, the concept was reduced to 7 factors (Cronbach's alpha 0.79): assessment of practical actions aimed at health maintenance and their adequacy; readiness to change the lifestyle immediately or on a child's suggestion; the nature and intensity of physical activity; assessment of the lifestyle as a healthy one.

Factor analysis identified two elements: the introduction of a healthy lifestyle (in particular, the intensity of physical activity, and other practical measures already underway) and motivation for changes (assessment of the adequacy of health measures, readiness to change the lifestyle). 
For better understanding of motivation, 15 factors were added to the concept that described the beliefs and activities of doctors regarding health maintenance of their children:

1) parents' conviction about the need for their children to comply with health maintenance measures (HMM) (8 factors, hereinafter - «compliance with HMM»);

2) health promotion activities which they undertake in relation to their children ( 7 factors, hereinafter - «promotion»).

Factors of compliance with HMM and promotion showed high levels of internal consistency (Cronbach's alpha 0.899 and 0.898 , respectively) and were monofactorial according to factor analysis.

On the basis of two elements of readiness to the lifestyle change, as well as the average assessment of the elements of compliance with HMM and promotion, two clusters were formed (coincidence of groups formed by hierarchical and non-hierarchical methods was more than $81.6 \%$ ).

Cluster analysis on the factors of readiness to take actions aimed at health maintenance revealed two groups of doctors (Table 4): willing and unwilling to implement them. The representatives of the first group have significantly lower proportion of smokers and a higher rating for the importance of habits in preventing NCDs.

Table 4

Groups of doctors by elements of readiness to take actions aimed at health maintenance

\begin{tabular}{rcccccccc}
\hline & \multicolumn{3}{c}{ Factor scores, Mean \pm SD } & & \multicolumn{3}{c}{ Moderator } \\
\cline { 2 - 9 } Cluster & $\begin{array}{c}\text { Implementation } \\
\text { of a healthy } \\
\text { lifestyle }\end{array}$ & $\begin{array}{c}\text { Motivation } \\
\text { for changes }\end{array}$ & $\begin{array}{c}\text { Compliance } \\
\text { with } \\
\text { HMM** }\end{array}$ & Promotion*** & $\begin{array}{c}\text { Smokers, } \\
\%\end{array}$ & $\begin{array}{c}\text { NCD in } \\
\text { doctors, } \\
\%\end{array}$ & $\begin{array}{c}\text { NCD in } \\
\text { relatives, } \\
\%\end{array}$ & $\begin{array}{c}\text { Habits vs } \\
\text { medicine }\end{array}$ \\
\hline 1 (98 pers.) & $0.31 \pm 0.9$ & $0.45 \pm 0.7$ & $9.7 \pm 0.5$ & $8.0 \pm 1.4$ & $10.2^{*}$ & 55.1 & 80.6 & $8.4 *$ \\
2 (60 pers.) & $-0.39 \pm 0.94$ & $-0.80 \pm 0.97$ & $9.1 \pm 1.3$ & $4.8 \pm 2.0$ & 21.7 & 63.3 & 86.4 & 7.4
\end{tabular}

Note: * the moderator has statistically significant difference at the level of $p<0.05$ from other clusters. Factor scores are mainly in the range from -3 to +3 , except the factors marked by ** which variated from 1 to 10

To identify the determinants of self-assessment of the lifestyle compliance with the concept of «healthy», among the questions of the last concept there was chosen one that is both quite general and describes the attitude to the healthy lifestyle, and at the same time has the greatest variability of answers. This question was: «10.13. Do you think you lead a healthy lifestyle?» The answer to this question was given on a 10-point Likert scale from «No, radical changes are needed» to «Yes, there is nothing to improve».

At the first stage of regression analysis, monofactorial models were prepared for individual demographic factors, factors of the locus of control concept, the influence of the environment on behavior, myths about NCDs, etc., as well as estimated elements and clusters (except for those in the formation of which factor 10.13 was used). As a result, 7 factors were selected, where $R^{2}$ was more than 0.1 (they established model 1) and another 14 factors with $R^{2}$ of $0.05-0.1$ (first 7 factors and another 14 factors established model 2).

The first model consisted of four factors (adequacy of actions aimed at health maintenance; the need for lifestyle change; the impact of diet on health; the nature of physical activity during the last week), $R^{2}$ was 0.381 .

The second model was built on 21 factors; it had 7 statistically significant independent variables, and $R^{2}$ was 0.498 .

Table 5 shows that the factors that positively affect a person's assessment of the lifestyle as a healthy one are the intensity and adequacy of appropriate preventive measures, quitting smoking and maintaining a healthy diet, approval of the lifestyle by social surrounding. A negative factor is the need to change the lifestyle: the greater the need for a doctor to change the lifestyle, the less likely he is to consider it healthy. 
Table 5

Determinants of self-assessment of the lifestyle as a healthy one in doctors (model 2)

\begin{tabular}{|c|c|c|c|c|}
\hline No. & Factor & Rating & $\begin{array}{c}\text { Standardized } \\
\text { Coefficients (Beta) }\end{array}$ & Sig. \\
\hline 1. & $\begin{array}{l}\text { How sufficient, in your opinion, are your ac- } \\
\text { tions aimed at health maintenance? }\end{array}$ & $\begin{array}{l}1 \text { I do not do anything. } \\
10 \text { More than enough }\end{array}$ & 0.228 & 0.003 \\
\hline 2. & $\begin{array}{l}\text { How much do you feel the need for lifestyle } \\
\text { changes (to stay healthy)? }\end{array}$ & $\begin{array}{l}1 \text { I do not feel any need. } \\
10 \text { I feel a critical need }\end{array}$ & -0.305 & 0.000 \\
\hline 3. & Do you smoke? & $\begin{array}{l}1 \text { Yes. } \\
2 \text { No }\end{array}$ & 0.172 & 0.009 \\
\hline 4. & $\begin{array}{l}\text { How can you evaluate practical measures } \\
\text { aimed at lifestyle changes that you take? }\end{array}$ & $\begin{array}{l}1 \text { I do not take and do not plan any. } \\
10 \text { I take a number of actions every day }\end{array}$ & 0.158 & 0.027 \\
\hline 5. & $\begin{array}{l}\text { Are there any factors in your behavior that } \\
\text { your friends or family members would like to } \\
\text { change to improve your health? }\end{array}$ & $\begin{array}{l}1 \text { Yes. } \\
2 \text { No. } \\
3 \text { Other }\end{array}$ & 0.159 & 0.016 \\
\hline 6. & $\begin{array}{l}\text { How and to what extent the diet influences the } \\
\text { maintenance or implementation of health pre- } \\
\text { servation practices? }\end{array}$ & $\begin{array}{l}1 \text { It does not promote health (it harms } \\
\text { health). } \\
10 \text { It promotes health }\end{array}$ & 0.192 & 0.009 \\
\hline 7. & $\begin{array}{l}\text { How often do you talk about bad habits with } \\
\text { patients on your own initiative? }\end{array}$ & $\begin{array}{l}1 \text { Never. } \\
10 \text { Every day }\end{array}$ & 0.159 & 0.015 \\
\hline
\end{tabular}

It is interesting that doctors who are more likely to talk to patients about bad habits on their own initiative tend to consider their lifestyle healthier. This is probably indicative of inverse relationship: doctors who take care of their health are more attentive to their patients' health.

At the same time, there is no statistically significant relationship between the assessment of the lifestyle as a healthy one and the following factors:

1) the need for children to follow the recommendations on salt intake, healthy eating and daily regimen;

2) the nature and intensity of physical activity during the last week;

3) being an example of living a healthy lifestyle for a child;

4) readiness for immediate lifestyle changes;

5) assessment of health impact of such factors as daily regimen, financial situation, busyness, mood, environmental factors;

6) assessment of the financial appeal of human health;

7) health maintenance as the number one factor.

\section{Discussion of research results}

The concepts proposed for analysis illustrate various aspects of decision-making on choosing and leading a healthy lifestyle.

The concept of myths about NCDs provides information about the theoretical knowledge of respondents, the degree of risks and opportunities, etc. Identifying groups of people who are insufficiently informed about the importance of NCDs in Ukraine and in the world (cluster 3), high risk of NCDs for everyone and available preventive methods (cluster 2,3), the negative impact of disease burden on the financial situation of both the country and the person (cluster 3, 4) allows us to clarify the messages of information campaigns and send them directly to the recipient.

The concept of the locus of control more adequately reflects doctors' beliefs about responsibility for health than the direct question of the degree of self-responsibility. The clusters obtained on the basis of a three-factor model demonstrate groups of doctors with predominantly external (cluster 1, 4) and internal (cluster 2, 3) locus of control, as well as help choose more effective opportunities to raise the awareness on health, as those who place responsibility, for example, on public authorities, are more likely to listen to their messages than those who do not think so. 
The analysis of the factors influencing health behavior showed significantly lower levels of NCD prevalence among those who identified all three factors as favorable: lifestyle, constant environment and information exchange. This fact certainly needs further study, including establishing exposure-response relationship. The selected subgroups of people more and less willing to take practical measures aimed at health maintenance have statistically significant differences in the proportion of smokers and assessment of the importance of habits in NCD development.

In general, the selected subgroups (clusters) of respondents are a simple and effective method of building a better understanding of the target audience of campaigns to promote healthy lifestyles, which after proper clarification, verification and development of a reliable measurement tool can be used to create targeted messages for each population group.

The list of identified determinants of the lifestyle assessment as a healthy one, which includes such factors of prevention as healthy diet and quitting smoking, focusing on the application component, sensitivity to the position of social environment indicates a satisfactory understanding of the main determinants of NCDs. At the same time, the share of smokers and the analysis of concepts by elements and clusters indicate both the existence of gaps in the information support of doctors (knowledge of basic epidemiological indicators of NCDs, economic dimension, etc.) and their lack of knowledge or resources to implement healthy practices in their life.

The research [20] was found 5 groups of people according to their health behavior: Unconfident Fatalists, Live for Todays, Hedonistic Immortals, Balanced Compensators, Health-conscious Realists. The final solution was based on 16 factors incl. self-esteem and self-efficacy, health consciousness, goal setting, risk-taking, intention to lead a healthy lifestyle, health locus of control, aspirations, response efficacy, short-termism so on.

In the research $[16,21] 15$ factors in 2 domains were analyzed. In the Social/environmental domain perceived social support, peer-group norms, interpersonal communication, and in the Internal/personal domain perceived personal risk, self-efficacy, hedonistic attitude, health as a value, etc. were investigated. As a result of research, the 9 segments of the Hungarian population were found: Aspiring Attractives, Passives at Risk, Moderate Dependents, Impulsive Hedonists, Careless Gourmets, Health-conscious Passives, Smoking Addicts, Non-interested Nihilists, Self-destructive Nihilists.

Study limitations. The article analyzes only the data of physicians who agreed to fulfill the questionnaire. The survey was conducted only in the web-based form: it is possible physicians who do not use the Internet will have different behavior.

Prospects for further research. Development and verification of the effectiveness of interventions based on established behavioral differences.

\section{Conclusions}

The analysis of the responses of 167 doctors from all regions of Ukraine allowed us to identify the main elements (factors) involved in the development of information component of NCD prevention. In particular, three elements of the locus of control on personal health are identified: directive (government), collective (community) and proactive (individual); three elements influencing health behavior: lifestyle (internal environment), constant environment (external environment) and sociability (information acquisition); two elements of readiness to take actions: implementation of a healthy lifestyle and motivation for changes.

The regression analysis identified seven factors related to a person's assessment of the lifestyle as a healthy one, including the need for lifestyle changes, the intensity and adequacy of appropriate preventive measures, quitting smoking and maintaining a healthy diet, approval of the lifestyle by social surrounding, initiating the discussion of bad habits with patients.

The obtained results can be used to build a targeted communication in the field of public health after a proper clarification and verification.

\section{Conflict of interests}

The authors declare that they have no conflicts of interest. 


\section{References}

[1] World Health Organization. Global action plan for the prevention and control of non-communicable diseases 2013-2020 (2013). Geneva, 103.

[2] World Health Organization. Global action plan on physical activity 2018-2030: more active people for a healthier world (2018). Geneva, 104.

[3] World Health Organization. Non-communicable diseases country profiles 2018 (2018). Geneva, 223.

[4] Abraham, T. (2010). The price of poor pandemic communication. British Medical Journal, 340. doi: http://doi.org/10.1136/ bmj.c2952

[5] Znamenska, M. A. (2015). Medyko-sotsialne obgruntuvannia systemy komunikatsii v okhoroni zdorovia. Kyiv: NMAPO imeni P.L. Shupyka, 316.

[6] Tonsaker, T., Bartlett, G., Trpkov, C. (2014). Health information on the Internet. Gold mine or minefield? Can Fam Physician, 60 (5), 407-408.

[7] Nejašmić, D., Miošić, I., Vrdoljak, D., Permozer Hajdarović, S., Tomičić, M., Gmajnić, R. et. al. (2017). Awareness and use of evidence-based medicine information among patients in Croatia: a nation-wide cross-sectional study. Croatian Medical Journal, 58 (4), 300-301. doi: http://doi.org/10.3325/cmj.2017.58.300

[8] Tan, S. S.-L., Goonawardene, N. (2017). Internet Health Information Seeking and the Patient-Physician Relationship: A Systematic Review. Journal of Medical Internet Research, 19 (1), e9. doi: http://doi.org/10.2196/jmir.5729

[9] Craig Lefebvre, R., Flora, J. A. (1988). Social Marketing and Public Health Intervention. Health Education Quarterly, 15 (3), 299-315. doi: http://doi.org/10.1177/109019818801500305

[10] Grier, S., Bryant, C. A. (2005). Social marketing in public health. Annual Review of Public Health, 26 (1), 319-339. doi: http:// doi.org/10.1146/annurev.publhealth.26.021304.144610

[11] Rothschild, M. L. (1999). Carrots, Sticks, and Promises: A Conceptual Framework for the Management of Public Health and Social Issue Behaviors. Journal of Marketing, 63 (4), 24-37. doi: http://doi.org/10.2307/1251972

[12] Hong, C., Kotler, P., Nancy, L. (2009). Social Marketing for Public Health: Global Trends and Success Stories. Jones \& Bartlett Learning.

[13] Vuik, S. I., Mayer, E., Darzi, A. (2016). A quantitative evidence base for population health: applying utilization-based cluster analysis to segment a patient population. Population Health Metrics, 14 (1). doi: http://doi.org/10.1186/s12963-016-0115-Z

[14] Balashov, K. V., Slabkii, G. O., Gulchii, O. P., Zakharova, N. M. (2020). Conceptual framework of psychographic research in the field of prevention of non-communicable diseases. Ukrainian Medical Journal, 139. doi: http://doi.org/10.32471/ umj.1680-3051.139.191002

[15] European Centre for Disease Prevention and Control. Social marketing guide for public health managers and practitioners (2014). Stockholm. doi: http://doi.org/10.2900/41449

[16] Balku, E., Tóth, G., Nárai, E., Zsiros, E., Varsányi, P., Vitrai, J. (2017). Methodology for identification of healthstyles for developing effective behavior change interventions. Journal of Public Health, 25 (4), 387-400. doi: http://doi.org/10.1007/s10389-017-0799-y

[17] Betsch, C., Böhm, R., Airhihenbuwa, C. O., Butler, R., Chapman, G. B., Haase, N. et. al. (2016). Improving Medical Decision Making and Health Promotion through Culture-Sensitive Health Communication. Medical Decision Making, 36(7), 811-833. doi: http://doi.org/10.1177/0272989x15600434

[18] Engl, E., Smittenaar, P., Sgaier, S. K. (2019). Identifying population segments for effective intervention design and targeting using unsupervised machine learning: an end-to-end guide. Gates Open Research, 3, 1503. doi: http://doi.org/10.12688/ gatesopenres.13029.2

[19] Slater, M. D., Flora, J. A. (1991). Health Lifestyles: Audience Segmentation Analysis for Public Health Interventions. Health Education Quarterly, 18 (2), 221-233. doi: http://doi.org/10.1177/109019819101800207

[20] Smith, A., Humphreys, S., Heslington, L., La Placa, V., Mcvey, D., MacGregor, E. (2011). The healthy foundations life-stage segmentation. Research report no. 2: The qualitative analysis of the motivation segments.

[21] Nárai, E. (2009). Healthstyle segmentation, attitudes to health. Eötvös Loránd University.

How to cite: Balashov, K., Hulchiy, O., Slabkiy, G. (2021). Evaluation of doctors' assessment of healthy lifestyle: cross-sectional study. EUREKA: Health Sciences, 2, 16-23. doi: http://doi.org/10.21303/2504-5679.2021.001709 